From the American

Board of Family Medicine

Ann Fam Med 2006:4:468-469. DOI: 10.1370/afm.637.

\section{MC-FP EARLY START, EM/FM COMBINED PROGRAM}

\section{ABFM Announces MC-FP Early Start}

In response to the many requests received from Diplomates, the American Board of Family Medicine (ABFM) is pleased to announce that it has accelerated many of the changes to Maintenance of Certification for Family Physicians (MC-FP) that were to have gone into effect in January 2007. These new features, collectively called Early Start, went into effect May 18, 2006.

With the change from an annual deadline to a 3-year Stage, Diplomates now have the chance to work ahead and complete each stage's requirements as early in the stage as they choose. This new option differs from the previous MC-FP plan, which required the completion of one MC-FP component per calendar year, thus restricting participants to a January 1 through December 31 timeline for completion. This modification relieves the pressure that the old annual requirements and the end-ofyear rush to complete them created for some Diplomates.

Additionally, Diplomates already in progress in MC-FP who decided to do extra modules for CME credit will be given credit for these modules as part of their first 3-year Stage. Please note, the reworking of the Web site to reflect the changes necessary for MCFP 2007 will not be complete until the end of 2006 Therefore, the "Track Your Progress" page will continue to illustrate the previous format and requirements of MC-FP; however, credit will be shown for completing the extra modules.

Finally, while the ABFM had already announced the elimination of late fees in 2007, again in keeping with the switch from an annual requirement to the 3-year Stage, the ABFM has eliminated late fees in 2006 as well. The ABFM hopes that ushering in as many of the new beneficial features to MC-FP as soon as possible will provide Diplomates with the flexibility to make the MC-FP process smoother and more efficient.

Please visit the ABFM Web site http://www.theabfm. org to learn more about MC-FP.

\section{Emergency Medicine/Family Medicine Combined Training Program}

The American Board of Emergency Medicine (ABEM) and the American Board of Family Medicine (ABFM) have approved guidelines for a 5 -year combined training program that, upon completion, will provide graduates the opportunity to seek certification in both emergency medicine (EM) and family medicine (FM). The following guidelines are applicable to residents entering training on and after July 1, 2006.

In 2005, the ABEM and the ABFM initiated discussions that focused on the interface between EM and FM. The Boards recognized that as the practice of medicine is rapidly changing, there may exist the opportunity to develop new training options for individual physicians and improve care for patients.

James C. Puffer, MD, President and Chief Executive Officer of the ABFM, sees the new opportunities for combined EM and FM residencies as progress toward fulfilling future manpower needs in Medicine. "In creating this combined program, both Boards envisioned opportunities to improve the quality of care delivered to the American public in every emergency department in the United States, to provide a training pipeline for physicians who had a strong desire to situate themselves in areas of health manpower need, and to develop a cadre of well-trained physicians who would serve as the unique interface between Departments of Family Medicine and Emergency Medicine within academic health centers and community hospitals across the country," says Dr. Puffer.

\section{Objectives}

Combined training in Emergency Medicine and Family Medicine (EM/FM) should develop physicians who are fully qualified in both specialties. The strengths of the two residencies should complement each other to provide the optimal educational experience.

The objectives of the combined training in EM/ FM include the training of physicians for practice or academic careers that address the spectrum of patient illness and injury from the emergent through the total health care of the individual and the family. Graduates of the combined training program may function as generalists, practice either or both disciplines, enter subspecialty training programs approved by either Board, or undertake research. Within an institution, their perspective spanning two specialties has the potential to increase communication and understanding.

Both boards identified six months of redundancy in the EM and FM training requirements while assuring that EM and FM requirements would be met. Combined programs will include components of categorical EM and FM residencies that are accredited respectively by the Residency Review Committee (RRC) for EM and the RRC for FM, both of which function under the auspices of the Accreditation Council for Graduate Medical Education (ACGME). Combined programs 
will be approved by the ABEM and the ABFM, with each categorical program being accredited by its respective RRC. Combined training in EM/FM is the sole recognized pathway for EM residents to train in family medicine and the sole recognized pathway for FM residents to train in emergency medicine, other than completion of both categorical EM and FM residency programs accredited by the ACGME.

After completion of a combined EM/FM residency program, the graduate will be eligible to sit for certification in each specialty. The Boards will not accept training in a combined program if the accreditation status of the residency in either primary discipline is probationary. If the residency in either discipline receives probationary accreditation after initiation of the combined training program, new residents may not be appointed to the combined training program until such time as the residency in the primary discipline is restored to full accreditation.

\section{General Requirements}

A combined EM/FM residency consists of 5 years of balanced training in the two disciplines that meets the ACGME Common Program Requirements, the Program Requirements for Residency Education in Emergency Medicine, and the Program Requirements for Residency Education in Family Medicine.

It is strongly recommended that the participating residencies be in the same academic health center, and documentation of hospital and university commitment to the program, where applicable, must be available in signed agreements. Such agreements must include institutional goals for the combined program. Participating institutions must be located close enough to facilitate cohesion among the program's house staff, attendance at weekly conferences, continuity clinics and integrated conferences, and faculty exchanges over curriculum, evaluations, administration, and related matters.

Ideally, at least two residents should be enrolled in each year of the 5-year program to ensure peer interaction. The total number of residents in combined programs may not exceed the number of residents in the categorical program of either specialty.

The training of residents while on EM rotations is the responsibility of the faculty of emergency medicine. Likewise, the training of residents while on FM rotations is the responsibility of the family medicine faculty. Prior to the completion of training, each resident must demonstrate some form of acceptable scholarly activity. Scholarly activity may include original research, comprehensive case reports, or review of assigned clinical and research topics.

Vacations, sick leave, and leave for meetings must be shared equally by both training programs. Absences from the training program exceeding five months in the 60 months must be made up.

\section{Application for Combined Training in EM/FM}

ACGME-accredited EM and FM residencies interested in developing an Emergency Medicine/Family Medicine combined training program should contact either the ABEM or the ABFM for an application packet. The completed application materials must be submitted to both Boards for review, and both Boards must approve the program before it enrolls residents.

Upon successful completion of the combined training program, a resident must submit the appropriate applications to the ABEM and the ABFM to enter the certification process.

More information for this combined residency training program in emergency medicine and family medicine is available at the ABFM Web site, http://www.theabfm.org.

\author{
Robert Cattoi \\ American Board of Family Medicine
}

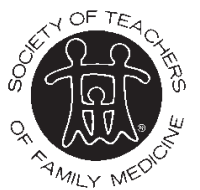

From the Society of Teachers of Family Medicine

Ann Fam Med 2006;4:469-470. DOI: 10.1370/afm.635.

\section{STFM NEW PARTNERS INITIATIVE: A PRODUCTIVE FIRST YEAR!}

The Society of Teachers of Family Medicine (STFM) established the New Partners Initiative (NPI) as a way to develop the people and mechanisms to enhance the long-term support and viability of family medicine programs. By emphasizing the importance of building relationships and identifying mutual interests with private, public, governmental, and foundation partners, the NPI is intended to help STFM lead academic family medicine in recognizing the need for combining financial development and sustainability with program quality and success. Ultimately important is the outcome of optimistic attitudes, ownership, and skills among family medicine organizations, faculty, and administration who appreciate the issues of long-term support for our efforts and understand how to incorporate the financial aspects at the forefront of planning.

The NPI is composed of 3 parts: the New Partners Think Tank, which provides overall guidance and direction for the project; the New Partners Academic Fund-raising Fellowship (AFF), which offers workshops, 